\title{
Effectiveness of the professional who carries out the health education program: perinatal outcomes
}

This article was published in the following Dove Press journal:

International Journal of Women's Health

19 March 2014

Number of times this article has been viewed

\section{Juan Miguel Martínez- Galianol-3 \\ Miguel Delgado- \\ Rodríguez ${ }^{2,3}$}

'Hospital San Juan de la Cruz, Ubeda, ${ }^{2}$ Department of Health Sciences, University of Jaén, Jaén, ${ }^{3}$ Biomedical Research Centre Network for Epidemiology and Public Health, Ministry of Health, Institute of Health Carlos III, Madrid, Spain

Correspondence: Juan Miguel MartínezGaliano

Universidad de Jaén Campus de Las Lagunillas, s/n Edificio B3, Despacho 4I3, 2307I Jaén, Spain

Email juanmimartinezg@hotmail.com
Background: The purpose of this study was to determine whether a maternal education program conducted by midwives achieves better results in regard to maternal and newborn health than when the program is conducted by other health professionals.

Methods: Five hundred and twenty primiparous women attending four (two university) public hospitals in southern Spain in 2011 were recruited to participate in this prospective cohort study. Data on sociodemographic and obstetric variables and characteristics of newborns were collected by interviews and from clinical charts. Crude and logistic regression adjusted odds ratios (aORs) and confidence intervals (CIs) were estimated.

Results: A midwife was in charge of education for $75.4 \%$ of the 354 women who attended maternal education programs. Midwife-conducted programs had significantly more women attending more than three sessions than the programs conducted by other health professionals (aOR 2.85, 95\% CI 1.60-5.11). Midwives achieved more active participation from mothers during delivery (aOR 1.96, 95\% CI 1.15-3.33), more early skin-to-skin contact between the mother and newborn (aOR 1.79, 95\% CI 1.01-3.23), more early breastfeeding (aOR 2.08, 95\% CI 1.18-3.70), and fewer newborns with low birth weight (aOR 0.14, 95\% CI 0.03-0.65) compared with other health professionals.

Conclusion: Midwives achieve better results than other health professionals in regard to the health of the mother and her newborn when they are in charge of the maternal education program.

Keywords: maternal education program, midwifery, childbirth, other health professionals

\section{Introduction}

In many countries, maternal education aims to influence health behavior, increase women's confidence in their ability to give birth, prepare women and their partners for childbirth, develop social networks of support, promote parental safety, and reduce perinatal morbidity and mortality. Therefore, maternal education comprises a range of educational and support services that help parents to understand their own social, emotional, psychological, and physical needs during pregnancy. ${ }^{1}$ In Spain, maternal education programs can be carried out by both midwives and nurses within the national health system, with universal and free access offered at all health centers. Most of the program is carried out in group sessions in the third trimester of pregnancy, and includes appropriate information about life styles, theory about pregnancy, physical and psychological preparation for delivery, and care of the newborn (there are conferences and physical exercise classes). ${ }^{2}$ Studies from a number of countries have evaluated the effectiveness of maternal education programs. ${ }^{3-6}$ However, less than $50 \%$ of women attend 
a maternal education program in Spain..$^{7-10}$ The World Health Organization recommends changing the perinatal health care model towards more user-orientated assistance. ${ }^{11}$

To our knowledge, no study as yet has assessed the effect of type of educator on maternal health education. In Spain, midwives have the same training as nurses, but also receive postgraduate training in theory and practice focused on the process of pregnancy, childbirth, and the postpartum period, which is not routinely received by general nurses. Nurses participating in the program are taught previously by midwives. The program of maternal education is standardized for all the Andalusian public health system, and midwives and nurses use the same units. In theory, teachers (midwives) have better training than students (nurses) and could achieve better delivery outcomes. The present study evaluates this assumption.

\section{Materials and methods}

A prospective cohort multicenter study was conducted between January 2011 and January 2012 in four hospitals in the public health system (University Hospital of Jaén, Hospital of Ubeda, Hospital of El Ejido, and University Hospital Virgen de las Nieves of Granada) across three provinces of Andalusia, Spain. The reference population was comprised of women who gave birth and met the study inclusion criteria of being primiparous, having a single pregnancy, and aged $\geq 18$ years. The study was approved by the ethics committee of each center. All women provided their informed consent. Women who did not speak Spanish were excluded.

A total of 539 women were approached and 19 refused to participate. Of the 520 remaining women (number of cases collected at each hospital was proportional to the number of births, ie, 201 at the University Hospital Virgen de las Nieves of Granada, 132 at the Hospital of Jaén, 127 at the Hospital de Poniente of El Ejido, and 60 cases in the Hospital of Ubeda), 354 attended a maternal education program. Women meeting the inclusion criteria were selected consecutively.

Information was collected on the sociodemographic characteristics of the mother, living conditions during pregnancy, obstetric variables, anthropometric measurements for the newborn (weight, height, head circumference), Apgar score at 1 and 5 minutes, need for neonatal hospital admission (and length of stay), and neonatal illness in the first 2 months of life. Spain-appropriate growth curves published by Delgado Beltrán et al were used to identify small for gestational age newborns. ${ }^{12,13}$ Neonates weighing $<2,500 \mathrm{~g}$ were considered to be low birth weight. ${ }^{14}$ Data were also gathered on the women's satisfaction with their health care during pregnancy, with the attention they received during delivery, and with the maternal education program. The women were followed for up to 3 months after delivery to collect data on breastfeeding. The Spanish version of the Hospital Anxiety and Depression scale developed by Zigmond and Snaith ${ }^{15}$ was used to assess the level of maternal anxiety before delivery. The data were collected from clinical charts and personal interviews. A 140-item questionnaire (130 closed and ten open items) was applied by 24 trained interviewers.

For data analysis, odds ratios and 95\% confidence intervals (CIs) were estimated for categorical variables. In multivariate analysis, logistic regression was applied to obtain adjusted odds ratios (aORs), retaining variables that altered the coefficient of the main exposure in more than $10 \%$ as confounding variables. Sociodemographic characteristics and the presence of pathology during pregnancy were considered to be potential confounders. Means and standard errors were computed for continuous variables. Analysis of covariance was applied in multivariate analysis, adjusting for the same variables.

\section{Results}

Most of the women were Caucasian (98.6\%) and of Spanish nationality $(94.6 \%)$, with a mean age of $30.7 \pm 4.9$ years. Most were married (68.8\%), 38.7\% had completed university studies, $25.24 \%$ worked in the public service, $45.4 \%$ had an indefinite contract with an employer, $49.4 \%$ had an average income of 1,000-1,999 Euros per month, 85.6\% had no underlying diseases, and $92.1 \%$ had planned the pregnancy.

The relationship between the characteristics of the program and midwives is shown in Table 1. Midwives achieved more sessions and provided more hours of maternal education than other health professionals. The level of antepartum anxiety and reasons for seeking emergency obstetric care were not different between the two groups.

The relationship between maternal education programs conducted by midwives and characteristics of delivery is shown in Table 2 . The only significant relationships observed were a higher frequency of perineal lesions and more active maternal participation in delivery when maternal education was conducted by midwives compared with other health professionals.

The relationship between maternal education programs conducted by midwives and the outcome for the newborn is shown in Table 3. Midwives achieved a lower frequency of low birth weight neonates and fewer admissions to intensive 
Table I Relationship between type of educator teaching the maternal education program and program characteristics, emergency care, and antepartum anxiety

\begin{tabular}{|c|c|c|c|c|}
\hline & \multicolumn{2}{|c|}{ Maternal education by midwife } & \multirow{2}{*}{$\frac{\text { Crude analysis }}{\text { OR }(95 \% \mathrm{Cl})}$} & \multirow{2}{*}{$\begin{array}{l}\text { Multivariate analysis } \\
\text { OR }(95 \% \mathrm{Cl})\end{array}$} \\
\hline & No, n (\%) & Yes, n (\%) & & \\
\hline \multicolumn{5}{|c|}{ Maternal education sessions ( $\mathrm{n}$ ) } \\
\hline $1-3$ & $28(32.18)$ & $37(\mid 3.86)$ & I (ref) & I (ref)* \\
\hline$>3$ & $59(67.82)$ & $230(86.14)$ & $2.95(1.59-5.39)$ & $2.85(1.60-5.11)$ \\
\hline \multicolumn{5}{|c|}{ Hours of maternal education ( $n$ ) } \\
\hline $1-5$ & $30(35.30)$ & $47(17.67)$ & I (ref) & I (ref)* \\
\hline $6-10$ & $32(37.65)$ & $85(31.95)$ & $1.69(0.87-3.27)$ & $1.59(0.84-3.0)$ \\
\hline $11-15$ & $18(21.18)$ & $66(24.82)$ & $2.34(1.10-4.99)$ & $2.21(1.08-4.52)$ \\
\hline$>15$ & $5(5.87)$ & $68(25.56)$ & $8.68(2.99-30.34)$ & $8.06(2.87-22.6 \mathrm{I})$ \\
\hline$P$-value of trend & & & $<0.001$ & $<0.001$ \\
\hline \multicolumn{5}{|c|}{ Unnecessary emergency obstetric care } \\
\hline No & $54(62.07)$ & I $88(70.41)$ & I (ref) & I (ref)* \\
\hline Yes & $33(37.93)$ & $79(29.59)$ & $0.69(0.40-1.19)$ & $0.74(0.44-1.25)$ \\
\hline \multicolumn{5}{|c|}{ Antepartum anxiety level } \\
\hline Normal & 48 (55. I7) & I5I (56.77) & I (ref) & I (ref)* \\
\hline Higher & $39(44.83)$ & 115 (44.23) & $0.94(0.56-1.59)$ & $0.99(0.60-1.64)$ \\
\hline
\end{tabular}

Notes: *Adjusted for marital status, education level, presence of pathology during pregnancy, planned pregnancy, and maternal age.

Abbreviations: $\mathrm{Cl}$, confidence interval; OR, odds ratio; ref, reference.

Table 2 Relationship between type of educator teaching the maternal education program and characteristics of delivery

\begin{tabular}{|c|c|c|c|c|}
\hline & \multicolumn{2}{|c|}{ Maternal education by midwife } & \multirow{2}{*}{$\frac{\text { Crude analysis }}{\text { OR }(95 \% \mathrm{Cl})}$} & \multirow{2}{*}{$\begin{array}{l}\text { Multivariate analysis } \\
\text { OR }(95 \% \mathrm{Cl})\end{array}$} \\
\hline & No, n (\%) & Yes, n (\%) & & \\
\hline \multicolumn{5}{|l|}{ Type of delivery } \\
\hline Eutocic & $40(45.98)$ & $144(53.93)$ & I (ref) & I (ref)* \\
\hline Dystocic & $47(54.02)$ & $123(46.07)$ & $0.73(0.43-1.22)$ & $0.73(0.44-1.20)$ \\
\hline \multicolumn{5}{|l|}{ Delivery onset } \\
\hline Spontaneous & $45(51.72)$ & I5I (56.55) & I (ref) & I (ref)* \\
\hline Induced/planned & $42(48.28)$ & $116(43.45)$ & $0.83(0.49-1.39)$ & $0.81(0.49-1.33)$ \\
\hline \multicolumn{5}{|l|}{ Cesarean delivery } \\
\hline No & $66(75.86)$ & $226(84.64)$ & I (ref) & I (ref)* \\
\hline Yes & $21(24.14)$ & $41(15.36)$ & $0.57(0.30-1.09)$ & $0.56(0.30-1.03)$ \\
\hline \multicolumn{5}{|c|}{ Early skin-to-skin contact between mother and newborn } \\
\hline No & $25(28.74)$ & $52(19.55)$ & I (ref) & I (ref)* \\
\hline Yes & $62(71.26)$ & $214(80.45)$ & $1.67(0.91-3.03)$ & $1.79(1.01-3.23)$ \\
\hline \multicolumn{5}{|c|}{ Medication during dilation } \\
\hline No & $19(21.84)$ & $64(23.97)$ & I (ref) & I (ref)* \\
\hline Yes & $68(78.16)$ & $203(76.03)$ & $0.89(0.47-1.64)$ & $0.91(0.50-1.64)$ \\
\hline \multicolumn{5}{|c|}{ Use of epidural analgesia } \\
\hline No & II (I2.64) & $45(16.85)$ & I (ref) & I (ref)* \\
\hline \multirow[t]{2}{*}{ Yes } & $76(87.36)$ & $222(83.15)$ & $0.71(0.32-1.49)$ & $0.85(0.39-1.82)$ \\
\hline & & & Hay & \\
\hline \multicolumn{5}{|c|}{ Use of nonpharmacological analgesia during delivery } \\
\hline No & $70(80.46)$ & $210(78.65)$ & I (ref) & I (ref)* \\
\hline Yes & $17(19.54)$ & $57(21.35)$ & $1.12(0.60-2.17)$ & $1.19(0.63-2.22)$ \\
\hline \multicolumn{5}{|c|}{ Presence of perineal lesions } \\
\hline No & $30(34.48)$ & $59(22.10)$ & I (ref) & I (ref)* \\
\hline Yes & $57(65.52)$ & $208(77.90)$ & $1.85(1.05-3.23)$ & $1.89(1.09-3.23)$ \\
\hline \multicolumn{5}{|c|}{ Postpartum complications } \\
\hline No & $78(89.66)$ & $240(89.89)$ & I (ref) & I (ref)* \\
\hline Yes & $9(10.34)$ & $27(10.11)$ & $0.98(0.42-2.17)$ & $0.88(0.39-2.00)$ \\
\hline \multicolumn{5}{|c|}{ Active maternal participation in delivery } \\
\hline No & $32(36.78)$ & $61(22.85)$ & I (ref) & I (ref)** \\
\hline Yes & $55(63.22)$ & $206(77.15)$ & $1.96(1.12-3.45)$ & $1.96(1.15-3.33)$ \\
\hline
\end{tabular}

Notes: *Adjusted for marital status, education level, presence of pathology during pregnancy, planned pregnancy, and maternal age; **adjusted for marital status, education level, presence of pathology during pregnancy, planned pregnancy, maternal age, and use of epidural analgesia.

Abbreviations: $\mathrm{Cl}$, confidence interval; $\mathrm{OR}$, odds ratio; ref, reference. 
Table 3 Relationship between type of educator teaching the maternal education program and newborn characteristics

\begin{tabular}{|c|c|c|c|c|}
\hline \multirow[t]{2}{*}{ Variable } & \multicolumn{2}{|c|}{ Maternal education by midwife } & \multirow{2}{*}{$\frac{\text { Crude analysis }}{\text { OR }(95 \% \mathrm{Cl})}$} & \multirow{2}{*}{$\begin{array}{l}\text { Multivariate analysis } \\
\text { OR }(95 \% \mathrm{Cl})\end{array}$} \\
\hline & No, n (\%) & Yes, n (\%) & & \\
\hline \multicolumn{5}{|c|}{ Low birth weight $(<2,500 \mathrm{~g})$} \\
\hline No & $80(91.95)$ & $264(98.88)$ & I (ref) & I (ref)* \\
\hline Yes & $7(8.05)$ & $3(1.12)$ & $0.13(0.02-0.59)$ & $0.14(0.03-0.65)$ \\
\hline \multicolumn{5}{|c|}{ Small for gestational age } \\
\hline No & $67(77.01)$ & 208 (78.79) & I (ref) & I (ref)* \\
\hline Yes & $20(22.99)$ & $56(21.21)$ & $0.91(0.49-1.72)$ & $0.83(0.45-1.52)$ \\
\hline \multicolumn{5}{|c|}{ Admission to intensive care unit } \\
\hline No & $83(95.40)$ & $266(99.63)$ & I (ref) & I (ref)** \\
\hline Yes & $4(4.60)$ & $\mathrm{I}(0.37)$ & $0.08(0.00-0.8 \mathrm{I})$ & $0.09(0.01-0.88)$ \\
\hline \multicolumn{5}{|c|}{ Admission to neonatal unit } \\
\hline No & $6 I(70.11)$ & $239(89.5 \mathrm{I})$ & I (ref) & I (ref)** \\
\hline Yes & $26(29.89)$ & $28(10.49)$ & $0.27(0.14-0.53)$ & $0.32(0.16-0.66)$ \\
\hline \multicolumn{5}{|c|}{ Early initation of breastfeeding } \\
\hline No & $28(32.18)$ & $49(18.35)$ & I (ref) & I (ref)* \\
\hline Yes & $59(67.82)$ & $218(81.65)$ & $2.13(1.18-3.85)$ & $2.08(1.18-3.70)$ \\
\hline \multicolumn{5}{|c|}{ Maintenance of breastfeeding 2 months after delivery } \\
\hline No & $24(27.91)$ & $85(33.07)$ & I (ref) & I (ref)* \\
\hline Yes & $62(72.09)$ & $172(66.93)$ & $0.79(0.44-1.39)$ & $0.73(0.4 I-1.30)$ \\
\hline \multicolumn{5}{|c|}{ Health problems in the first 2 months of life } \\
\hline No & $68(80.00)$ & $218(83.85)$ & I (ref) & I (ref) ${ }^{* *}$ \\
\hline Yes & $17(20.00)$ & $42(16.15)$ & $0.78(0.40-1.56)$ & $0.8 \mathrm{I}(0.4 \mathrm{I}-\mathrm{I} .59)$ \\
\hline
\end{tabular}

Notes: *Adjusted for marital status, education level, presence of pathology during pregnancy, planned pregnancy, and maternal age; **adjusted for low birth weight, small for gestational age, presence of disease during pregnancy, cesarean delivery, and Apgar score at 5 minutes.

Abbreviations: $\mathrm{Cl}$, confidence interval; $\mathrm{OR}$, odds ratio; ref, reference.

care or neonatal units than other health professionals. The maternal education given by midwives also increased early initiation of breastfeeding and early skin-to-skin contact between the mother and newborn.

The relationship between maternal education programs conducted by midwives and several continuous variables is shown in Table 4. The only relevant associations were more satisfaction with the maternal education program and a higher opinion of the utility and benefits of the program when it was conducted by midwives than by other health professionals.

\section{Discussion}

To the best of our knowledge, no other report has compared midwives and other health professions in regard to the outcomes of maternal education programs. However, several studies have noted that women positively value the activities of midwives. ${ }^{16-18}$ This positive evaluation may be responsible for the differences seen in the present study, which imply that a maternal education program run by a midwife achieves the best outcome.

An indicator of the greater success achieved by midwives is that women attended more sessions when midwives conducted the program rather than other health professionals, which allows the benefits of the program to increase.
Midwives achieved more active involvement of the women during delivery, reduced the incidence of low birth weight, and decreased the number of newborn hospital admissions. Midwife-conducted programs also resulted in more frequent early skin-to-skin contact between the mother and newborn and early breastfeeding. Another Spanish study ${ }^{16}$ concluded that breastfeeding is favored by women who attend maternal education programs with midwives, although a comparison with other health professionals was not conducted. This early initiation of breastfeeding was not accompanied by a higher rate of breastfeeding 2 months after delivery.

However, maternal education by midwives has the disadvantage of an association with more perineal lesions during delivery. This may be due to the fact that midwives favor a policy of restrictive episiotomy, decreasing the number of surgical incisions; it may lead to the side effect of an increase of perineal lesions in women needing episiotomy who indicated her preference for avoiding the use of episiotomy. No effect was observed on the use of emergency obstetric care, degree of satisfaction with prenatal care and delivery, antepartum anxiety, type of delivery, duration of the different periods of delivery, gestational age, use of medication during dilation, complications after delivery, pain level reported during delivery, or use of epidural analgesia or alternative methods of pain relief. 
Table 4 Association between the type of educator teaching the maternal education program and continuous variables

\begin{tabular}{|c|c|c|c|c|c|c|}
\hline & \multicolumn{3}{|l|}{ Crude analysis } & \multicolumn{3}{|c|}{ Multivariate analysis } \\
\hline & \multicolumn{3}{|c|}{ Maternal education by midwife } & \multicolumn{3}{|c|}{ Maternal education by midwife } \\
\hline & $\begin{array}{l}\text { Yes, mean } \\
(95 \% \mathrm{Cl})\end{array}$ & $\begin{array}{l}\text { No, mean } \\
(95 \% \mathrm{Cl})\end{array}$ & $P$-value & $\begin{array}{l}\text { Yes, mean } \\
(95 \% \mathrm{Cl})\end{array}$ & $\begin{array}{l}\text { No, mean } \\
(95 \% \mathrm{Cl})\end{array}$ & $P$-value \\
\hline $\begin{array}{l}\text { Visits for unnecessary emergency } \\
\text { obstetric care (n) }\end{array}$ & $0.5(0.4-0.6)$ & $0.7(0.4-0.9)$ & $0.07 I$ & $0.5(0.4-0.6)$ & $0.6(0.4-0.8)$ & $0.235^{\#}$ \\
\hline $\begin{array}{l}\text { Pain level during delivery } \\
\text { (maximum 10) }\end{array}$ & $7.2(6.9-7.4)$ & $6.8(6.3-7.3)$ & 0.209 & $7.2(6.9-7.4)$ & $6.9(6.4-7.4)$ & $0.335^{\#}$ \\
\hline $\begin{array}{l}\text { Length of maternal hospital stay } \\
\text { after delivery }\end{array}$ & $2.3(2.2-2.4)$ & $2.6(2.3-2.9)$ & 0.094 & $2.4(2.3-2.5)$ & $2.4(2.2-2.5)$ & $0.847 * * *$ \\
\hline $\begin{array}{l}\text { Woman's satisfaction with control } \\
\text { of pregnancy }(0-4)\end{array}$ & $2.9(2.8-3.0)$ & $3.1(2.9-3.3)$ & 0.201 & $2.9(2.8-3.0)$ & $3.1(2.9-3.3)$ & $0.218^{\#}$ \\
\hline $\begin{array}{l}\text { Woman's satisfaction with the care } \\
\text { received during delivery }(0-4)\end{array}$ & $3.2(3.1-3.3)$ & $3.1(2.8-3.3)$ & 0.362 & $3.2(3.0-3.3)$ & $3.1(2.9-3.3)$ & $0.449 \ldots$ \\
\hline $\begin{array}{l}\text { Woman's satisfaction with the } \\
\text { maternal education program }(0-4)\end{array}$ & $3.0(2.9-3.1)$ & $2.5(2.3-2.7)$ & $<0.001$ & $3.0(2.9-3.1)$ & $2.5(2.3-2.7)$ & $<0.00 I^{\#}$ \\
\hline Gestational age at delivery & $39.5(39.2-39.8)$ & $39.5(39.2-39.8)$ & 0.958 & $39.5(39.2-39.8)$ & $39.5(39.1-39.9)$ & $0.976^{\#}$ \\
\hline Apgar score at I minute & $8.6(8.4-8.7)$ & $8.8(8.6-8.9)$ & 0.054 & $8.6(8.5-8.7)$ & $8.8(8.6-9.0)$ & $0.043^{*}$ \\
\hline Apgar score at 5 minutes & $9.3(9.3-9.4)$ & $9.3(9.2-9.4)$ & 0.710 & $9.3(9.3-9.4)$ & $9.3(9.2-9.4)$ & $0.747 *$ \\
\hline Length of neonatal hospital stay (days) & $2.4(2.2-2.4)$ & $2.9(2.3-3.4)$ & 0.024 & $2.5(2.3-2.6)$ & $2.7(2.3-3.0)$ & $0.328 * * *$ \\
\hline Duration of dilation (minutes) & $398.5(367.7-429.4)$ & $448.6(397.3-499.9)$ & 0.112 & $420.4(393.4-447.3)$ & $442.9(395.8-490.0)$ & $0.415^{* *}$ \\
\hline $\begin{array}{l}\text { Duration of expulsive period } \\
\text { (minutes) }\end{array}$ & $108.4(98.9-117.8)$ & $90.9(76.2-105.6)$ & 0.070 & $102.5(93.1-111.9)$ & $84.6(68.5-100.7)$ & $0.053 * *$ \\
\hline $\begin{array}{l}\text { Duration of the third period of } \\
\text { delivery (minutes) }\end{array}$ & $9.7(8.7-10.7)$ & $9.2(6.4-12.1)$ & 0.708 & $8.8(7.6-10.0)$ & $8.7(6.6-10.7)$ & $0.905 * *$ \\
\hline $\begin{array}{l}\text { Woman's opinion on the utility and } \\
\text { benefit of maternal education }(0-4)\end{array}$ & $3.1(3.0-3.2)$ & $2.7(2.5-3.0)$ & 0.002 & $3.1(3.0-3.2)$ & $2.8(2.6-3.0)$ & $0.006^{\#}$ \\
\hline
\end{tabular}

Notes: *Adjusted for low birth weight, small for gestational age, presence of disease during pregnancy, and cesarean delivery; **adjusted for type of delivery, induction of delivery, use of medication in dilation, use of epidural analgesia, maternal age, marital status, and education level; ***adjusted for cesarean delivery, neonatal hospital admission, presence of disease during pregnancy, and postpartum complications; \#adjusted for cesarean delivery, presence of disease during pregnancy, marital status, education level, and maternal age; \#adjusted for planned pregnancy, education level, marital status, presence of disease during pregnancy, and maternal age.

Abbreviations: $\mathrm{Cl}$, confidence interval; OR, odds ratio.

Some support for our results comes from a Cochrane review, ${ }^{19}$ although this did not have the primary goal of assessing the role and effectiveness of midwives versus other health professionals in maternal education. Several differences in the practices of midwives and other health professionals were noted in that review, ie, more frequent initiation of breastfeeding, fewer episiotomies, and fewer surgical deliveries. That review documents that the practice of midwives is directed more towards achieving specific goals, such as initiating breastfeeding and reducing instrumental deliveries, which may be due to their training and engagement with the actual experience of pregnancy, delivery, and the postpartum period. These practices are in agreement with the recommendations of the World Health Organization ${ }^{20}$ and different health agencies. ${ }^{11}$

Regarding the limitations of the present study, selection bias does not affect the results because the participation rate was very high. Confounding bias cannot be completely ruled out, and is a limitation inherent in most observational studies. We have collected and taken into account the most relevant variables influencing the outcome of delivery in multivariate analyses.
Misclassification bias is unlikely, because most of the variables are objective and do not allow for interpretation by the participants. In addition, the outcomes were verified using the clinical charts. Therefore, our study suggests that midwives achieve better results than other health professionals when they are in charge of maternal education programs.

\section{Acknowledgments}

The authors extend their gratitude to the women who participated as volunteers in this study and to the interviewers who assisted with data collection. This research was subsidized by the Health Research Fund of the Carlos III Health Institute (PI11/01388).

\section{Disclosure}

The authors report no conflicts of interest in this work.

\section{References}

1. Gagnon AJ, Sandall J. Individual or group antenatal education for childbirth or parenthood, or both. Cochrane Database Syst Rev. 2007;3:CD002869. 
2. Junta de Andalucia. [Consejeria of Health. Integrated Asistencial Process Pregnancy, Childbirth and Puerperium]. 2nd ed. Seville, Spain: Consejeria de Salud; 2005. Spanish.

3. Artieta-Pinedo I, Paz-Pascual C, Grandes G, et al. The benefits of antenatal education for the childbirth process in Spain. Nurs Res. 2010;59:194-202.

4. Fabian HM, Rådestad IJ, Waldenström U, et al. Childbirth and parenthood education classes in Sweden. 2005. Women's opinion and possible outcomes. Acta Obstet Gynecol Scand. 2005;84:436-443.

5. Araneda H, Cabrera C, Cabrera J, et al. [Prenatal education and its relation to the mode of delivery: a route to natural childbirth]. Rev Chil Obstet Ginecol. 2006;71:98-103. Spanish.

6. Consonni EB, Calderon IM, Consonni M, De Conti MH, Prevedel TTs, Rudge MV. A multidisciplinary program of preparation for childbirth and motherhood: maternal anxiety and perinatal outcomes. Reprod Health. 2010;29:28.

7. Márquez García A, Pozo Muñoz F, Sierra Ruiz M, et al. [Profile of pregnant women who do not go to a maternal education program]. Medicina de Familia (And). 2001;3:239-243. Available from: http:// www.samfyc.es/Revista/PDF/v2n3/original5.pdf. Accessed May 23, 2012. Spanish.

8. Goberna i Tricas J, García i Riesco P, Galvez i Lladó M. [Evaluation of the quality of prenatal care]. Aten Primaria. 1996;18:75-78. Spanish.

9. Tajada N, Bernués, A, López F, et al. [Prenatal health education: characteristics of participation in a health area]. Enferm Cientif. 1991;116:4-6. Spanish.

10. Pina F, Martínez ME, Rojas P, Campos M, Rodríguez MS. [The planning and maternal education favor the development of labor]. Enferm Clín. 1994;4:209-215. Spanish.

11. Ministry of Health and Social Policy. Clinical Practice Guidelines on Normal Childbirth Care. 1st ed. Vitoria, Brazil: Servicio Central de Publicaciones del Gobierno Vasco; 2010. Spanish.
12. Delgado Beltrán P, Melchor Marcos JC, Rodríguez-Alarcón Gómez J, et al. [Fetal development curves of newborns at the Hospital de Cruces (Vizcaya)]. II. Length, perimeter and ponderal index. An Es Pediatr. 1996;44:55-59. Spanish.

13. Delgado Beltrán P, Melchor Marcos JC, Rodríguez-Alarcón Gómez J, et al. [Fetal development curves of newborns at the Hospital de Cruces (Vizcaya)]. I. Weight. An Es Pediatr. 1996;44:50-54. Spanish.

14. Spanish Society of Gynecology and Obstetricia. [Perinatologic Definitions]. Madrid, Spain: SEGO; 2004. Spanish.

15. Vázquez Valverde C, Jiménez Franco F. Depression and mania. In: Bulbuena Vilarrasa A, Berrios GE, Fernández de Larrinoa Palacios P, editors. [Clinical Measurement in Psychiatry and Psychology]. 1st ed. Barcelona, Spain: Masson; 2003. Spanish.

16. García Mozo R, Alonso Sagredo L. [Valuation maternal prenatal measures to promote breastfeeding]. Aten Primaria. 2002;29:79-83. Spanish.

17. Torres Díaz A, Sánchez Fernández F, Martínez Martínez L, Fernández Cano E. [Opinion postpartum mothers about the program]. Matronas Prof. 2001;2:38-42. Spanish.

18. Hildingsson I, Waldenström U, Rådestad I. Women's expectations on antenatal care as assessed in early pregnancy: number of visits, continuity of caregiver and general content. Acta Obstet Gynecol Scand. 2002;81:118-125

19. Hatem M, Sandall J, Devane D, Soltani H, Gates S. Midwife-led versus other models of care for childbearing women. Cochrane Database Syst Rev. 2008;4:CD004667.

20. World Health Organization. Care in normal birth: a practical guide. Technical Working Group, World Health Organization. Birth. 1997;24: 121-123.
International Journal of Women's Health

\section{Publish your work in this journal}

The International Journal of Women's Health is an international, peerreviewed open-access journal publishing original research, reports, editorials, reviews and commentaries on all aspects of women's healthcare including gynecology, obstetrics, and breast cancer. The manuscript management system is completely online and includes

\section{Dovepress}

a very quick and fair peer-review system, which is all easy to use Visit http://www.dovepress.com/testimonials.php to read real quotes from published authors. 